\title{
ON ABDUCTION AND INTERPRETATION
}

Antonio Duarte

Universidad Complutense de Madrid

Facultad de Filosofía

Dept. Lógica y Filosofía Teórica

antduart@ucm.es

SUMMARY: Here, I focus on deviations of intent, from that expressed by the standard or ordinary use of language, in instances where abductive reasoning plays a necessary role. In such cases, speakers usually utter some "mysterious" words based on the assumed abductive capability of their interlocutors. In order to cause the desired effect in the audience, the speaker relies on the hearer's knowledge of the relevant common dialogue framework and thus uses the utterance as an abductive trigger. For purposes of explanation, I present a curious kind of (pseudo)fallacy: ironic (pseudo)fallacy.

KEY WORDS: abductive trigger, conversational implicature, Davidson, dialogue, fallacy

RESUMEN: En este artículo me centraré en desviaciones intencionales del uso ordinario del lenguaje desde una perspectiva en la que la abducción desempeña un papel necesario. En estos casos, el hablante profiere unas palabras "misteriosas" basándose en la capacidad abductiva del interlocutor. Con el fin de causar el efecto deseado, el hablante se apoya en el conocimiento, por parte del oyente, del marco dialógico compartido y utiliza su proferencia como un detonador abductivo. Con fines explicativos, presentaré un curioso tipo de (pseudo)falacia: la (pseudo)falacia irónica.

PALABRAS CLAVE: Davidson, detonador abductivo, diálogo, falacia, implicatura conversacional

\section{Introduction}

In this paper, I focus on deviations in a speaker's intent from that expressed by the standard or ordinary use of language, in instances where abductive reasoning plays a necessary role (Wirth 2001; Arrighi and Ferrairo 2008). This is closely connected to Davidson's work on intentional deviations from ordinary language usage, as in the case of jokes, puns and metaphors, where there is a "secret" message that has to be discovered (Davidson 2006). In such cases, the speaker usually utters some "mysterious" words based on the assumed abductive capability of their interlocutor. To arrive at a correct interpretation, the listener has to pay attention to pragmatic con- 
siderations, i.e., the context of the participants and the dialogue are essential. Thus, in order to cause the desired effect, the speaker relies on the listener's knowledge of the relevant common dialogue framework and thus uses the utterance as an abductive trigger (Aliseda 2006). In order to address a thorough examination of the interlocutor's context, the dialectical perspective of argumentation theory will be invoked.

According to pragma-dialectics (van Eemeren and Grootendorst 1984), there are certain rules that we have to observe when we are enrolled in a critical discussion (van Eemeren and Grootendorst 1987). In many instances of deviations in a speaker's intent, the "mysterious" words may be understood as violations of the discussion rules that frustrate the reasonable resolution of the difference of opinion and, therefore, these deviations could be regarded as fallacies. Thus, detecting a fallacy in the course of a dialogue may act as an abductive trigger and can help us to discover certain intentions of our interlocutor, at least as far as the interpretation of the utterance is concerned. This is the case in ironic (pseudo)fallacy, which is an ironic utterance analyzed on the basis of extended pragma-dialectics (van Eemeren 2010). The analysis shows that these kinds of utterances could be understood as legitimate strategic maneuvering which consists in shifting or evading the burden of proof based on the speaker's assessment of the abductive capability of the interlocutor. To resolve the situation, an abduction has to be made based on contextual elements, i.e., from the interlocutor's knowledge at that point in the exchange. Therefore, ironic (pseudo)fallacy will be a fallacy only if the abductive process is not triggered in the hearer or if the listener's abduction fails.

In addition, following this dialectical approach, the rapid, almost instantaneous, new hypothesis arrived at by abduction could be properly analyzed and criticized in a reasoned way.

The paper is structured into different sections. Section 2 is devoted to presenting the Peircean terms of abduction, insight, and logica docens. In Section 3, I focus on the dialogic approach to abduction, in order to find a methodology for this type of reasoning; while in Section 4, I connect abduction and Davidson's approach to interpretation. Then in Section 5, ironic (pseudo)fallacy is presented as a case where dialogue, traditional and pragma-dialectical fallacies, abduction, and interpretation interact in the course of resolving conversational implicature (Grice 1975). Finally, Section 6 offers some general conclusions. 


\section{Peircean Abduction}

Abduction is a type of reasoning in which a new idea is introduced and, moreover, where that idea is both tentative and relative to a given context. In Fann's words: "any synthetic proposition, whether it is a nonobservable entity or a generalization (so-called), in so far as it is for the first time entertained as possibly true, it is an hypothesis arrived at by abduction" (Fann 1970, pp. 33-34). Thus, through abduction, when we are faced with what can be regarded as surprising facts, we generate plausible hypotheses that can be tested by following the three stages of scientific research, as laid out by C.S. Peirce in his later work and which emerge from the three types of inference: abduction, deduction, induction. Accordingly, abduction could be considered as the whole process of both hypothesis generation and hypothesis evaluation following the three stages of scientific investigation (Peirce, ${ }^{1}$ CP 7.202-7.207, 1901, see e.g. Fann 1970; Anderson 1986). However, abduction is also understood as the inference that only generates plausible hypotheses: "Abduced hypotheses are adopted as a positive basis for action in various ways and for various reasons (only subclasses of abductive hypotheses are adopted only after a Peircean process of inductive empirical evaluation)." (Magnani 2009, p. 19)

While I note the distinction between abduction and inference to the best explanation (IBE) (see e.g. Magnani 2001; Aliseda 2006; Douven 2011; Wagemans 2014; Yu and Zenker 2017), here I will consider the abductive process as both hypothesis generation and hypothesis evaluation. When studying the differences between abduction and IBE, Yu and Zenker (2017) correctly point out that "the goal of IBE is to single out the 'best' explanation; the goal of abduction, by contrast, is to generate plausible explanations for further testing". Nevertheless, although a clear distinction between abduction and IBE is obviously possible, this may not be the case for the definitions of "generative" and "selective" abduction. Plausible hypotheses (understood as plausible explanatory abductions, see e.g. Gabbay and Woods 2005; Magnani 2009, pp. 63-144) arrived at by abduction (not IBE) have also been selected in some way, because these conjectures have to explain, at least vaguely, the data. Therefore, in agreement with Magnani (2001), I assume that "generative" abduction (hypothesis-conjecture) and "selective" abduction

\footnotetext{
${ }^{1}$ References to Peirce's works are from the Collected Papers of Charles Sanders Peirce $(C P)$, bracketed numbers refer to the volume, paragraph, and year of the text.
} 
(hypothesis-evaluation) occur as one inseparable process. I consider that this is the case in the interpretation process: the rapid abduction which leads to success in the communication process is usually a plausible and tentative explanation selected by a sort of preliminary IBE (see Section 5).

Peirce tells us: "The abductive suggestion comes to us like a flash. It is an act of insight, although of extremely fallible insight" (Peirce, CP 5.181, 1903). So, although the abductive process turns out to be somewhat instinctive, abduction involves an exercise in logica docens, i.e., a voluntary inquiry into the context that can lead us to the resolution of the enigma. As Anderson states: "For Peirce, abduction presupposes a certain amount of work by the investigator" (1986, p. 161). Therefore, by means of this insight, we illuminate a new idea that, perhaps, in a few seconds, will be a hypothesis. However, this "flash" comes about through rational and critical activity.

Peirce drew a distinction between the logic of men and women in their day-to-day lives and criticism, an incisive and more scientific logic; Peirce called them logica utens and logica docens, respectively (Peirce CP 2.188-2.190, 1902; CP 5.108, 1903; CP 5.130, 1903; Pietarinen 2005, p. 368; Chiasson 2001; Niño 2007, p. 142). Deliberate and critical reasoning is driven by logica docens, as opposed to the daily reasoning guided by our habits in which logica utens is the intermediary. In this sense, this concept of logica docens is broader than that adopted by the scholastic philosophers, for whom logica docens was the knowledge acquired through the study of logic. In short, in this paper I will refer to logica docens when the problem to be resolved is approached with a critical eye (Duarte 2018). In Fann's words: "by our logica utens we are able to guess right in many instances. [...] But, where our instinctive reasoning power begins to lose its self-confidence, as when we are confronted with extraordinary and unusual problems, we look to the help of our logica docens" (1970, p. 39).

\section{Methodology: A Dialogic Approach to Abduction}

Although there are no strict rules for abduction, we can discern a method for engaging in this type of voluntarily hypothesizing that leads to the generation of what we can consider to be "good" abductions. These "good" abductions are not identified with correct, true or infallible abductions, but with those that stand up to rational criticism; those in which we can argue for our choice because the latter explains, in some way, the data collected up to that point. 
The essays collected in Eco and Sebeok (1988) address the methodology adopted by famous fictional detectives that guides them towards good abductions. Hintikka (1998) distinguished between definitory rules, those that govern what is permissible when making inferences (the existent rules of transformation for deduction and induction); and strategic rules, those of abduction, which depend on context and are based on asking the right questions. Abduction is, therefore, usually presented in open circumstances, i.e., in situations where our knowledge is incomplete, and the process is not only one of reasoning, but also one of dialogue. As Hintikka points out, there is a close affinity between Peircean abduction and the interrogative model of inquiry, especially through explanation-seeking "why" questions: "Abductive 'inferences' must be constructed as answers to the inquirer's explicit or (usually) tacit questions put to some definitive source of answers (information)" (Hintikka, 1998, p. 519). Therefore, we could understand abduction as a dialectical process which can be explicit or implicit and progresses within specific dialogic frameworks. Moreover, in a context of dialogical logic, Barés Gómez and Fontain (2017) developed abductive dialogues based on the Gabbay and Woods schema of abduction (2005) and Aliseda's approach (2006) which are defined as not-conceded-preserving dialogues triggered by a concession problem: a hypothetical abductive solution overcomes a concession problem which allows the dialogues to continue. This conjecture is settled in a move allowed by additional rules. Meanwhile, Walton (2004) proposes certain phases through which abductive reasoning must pass in order to be critically evaluated. Paavola (2004) and Anderson (2005) also identify useful methodological points for effective abduction. Wagemans (2014) and $\mathrm{Yu}$ and Zenker (2017) develop an argumentative pattern along with critical questions based on the pragma-dialectical theory of argumentation for the assessment of argumentation based on abduction. From all that work, we can see that, both for generating and evaluating abduction, it is worth observing and analyzing certain methodological points or strategic rules related to scientific practice and to the very fallible nature of the new ideas that arise through abduction. If we are able to follow a certain methodology and to identify promising strategies, we can become aware of our abductive paths. In short, discerning a method for abduction is a matter of being able to subject abductions to criticism, both ours and that of other people.

In agreement with the argumentation scholars (Walton 2004; Wagemans 2014; Yu and Zenker 2017), I propose that the way to substantiate an abduction is through critical dialogue (Duarte 2015). 
Here, reasoned dialogue and argumentative patterns are understood as argumentative elements that allow us to establish a procedure for evaluating abductive hypotheses. These are also tools that could help move us toward new hypotheses.

Tools to assess argumentation, namely dialogue models, their rules and argumentative schemes, provide guidelines that allow us to evaluate arguments that arise within the dialectical process. More importantly, they enable us to assess whether the objectives of the dialogue are achieved in a reasonable way in accordance with the contextual framework. Thus, by integrating the abductive process into a model of reasoned dialogue, it can be treated as an exchange of arguments aimed at achieving a specific goal. In general, the aim of the dialogue is the resolution of an enigma and it is now presented as the resolution of a difference of opinion. This entire abductiveargumentative process can be evaluated through the use of the aforementioned tools, which may shed some light on appropriate ways to deal with abduction.

Walton (2004) proposed that we insert abduction into a specific dialogue framework. This moves us towards considering the context in a dialogic way. In Walton's proposal, any case of abductive reasoning proceeds through four phases: (1) dialogue setting; (2) the formation of explanation attempts within the dialogue; (3) evaluation of those explanations; and (4) dialogue closure.

It is within the setting of a dialogue that arguments lead us to accept or reject a hypothesis, as the premises of our commitment set are revealed. Through dialogue, we can, on the one hand, assess a hypothesis and on the other, create new hypotheses that may be suggested during the course of the conversation by means of the maieutic function of the dialogue. We could say that the process of asking and answering questions, or of making assertions and trying to argue for our own position, also activates the imagination of the researcher.

As a brief example of how the dialogue context and pragmatic considerations are crucial to evaluate abductions, we can explore a key aspect of an abduction made by the famous Sherlock Holmes. In The Adventure of the Blanched Soldier, Holmes has to investigate a disappearance and discover the reasons behind it. (Actually, it turns out to be a case of voluntary confinement due to a rather unpleasant disease.) Holmes solves the case by assuming that the soldier has contracted leprosy. However, the soldier's illness is diagnosed by a specialist doctor as a clear case of pseudoleprosy or ichthyosis (Doyle 2009). Holmes' abduction is appropriate, because it meets the 
specific objective of his investigation: to find the missing person. In the context of medical research, however, the abduction would have been a disaster for the patient! Note how the status of the soldier changes according to the objective of the dialogue: in a detective investigation, he is a missing person; while in medical research, he is a sick person. This shows that it is necessary to consider the dialogue framework to properly evaluate the hypothesis arrived at by abduction. Although the soldier had not contracted leprosy, in the "missing person" context this hypothesis could be considered an excellent abduction because it leads to resolving the case, i.e., to achieving the goal of the specific dialogue frame.

Application of Walton's phases to abduction, i.e., applying a dialectical-argumentative approach, stresses the following four aspects. (1) Both generation and evaluation of abductive hypotheses depend on the context; the dialogue setting determines what "kind" of hypothesis the researcher needs to solve the enigma. In the example, the hypothesis of the illness (leprosy) resolves Holmes' case, whereas a doctor could not have saved the patient using the same hypothesis. (2) Generation of new hypotheses and evaluation of those already established occur within a dialogue framework; explanation attempts revolve around the objective of the dialogue. To solve the case, Holmes could have given several explanations (murder, kidnapping, illness, etc.), but most of them very different from those potentially proposed by a doctor treating a patient. (3) The plausibility of a hypothesis is considered by taking into account the context, and the best explanation is chosen by referring to pragmatic considerations; for the evaluation of the explanations, although different, both Holmes' and the doctor's abductions are plausible taking into account their particular dialogue frame. (4) Finally, Walton's fourth phase is particularly connected to the defeasibility of abduction. The closure of the dialogue could be reconsidered and it is always possible to add new data to the commitment set.

\section{Abduction and Interpretation}

In this section, I present deviations of intent from those expressed by the standard or ordinary use of language, in instances where abductive reasoning plays a necessary role. In such cases, the speaker usually utters some "mysterious" words based on the assumed abductive capability of the interlocutor. To arrive at a correct interpretation, the context of the participants and the context of the dialogue are essential. 
In A Nice Derangement of Epitaphs, Davidson (2006) addresses the interpretation process that leads to understanding between interlocutors on speaker's intentional deviations from ordinary language usage. The following words of Davidson may be perfectly seen as conforming to Peirce's theory of abduction regarding hypothesis generation, selection and its fallibility:

An interpreter has, at any moment of a speech transaction, what I persist in calling a theory. (I call it a theory [...] only because a description of the interpreter's competence requires a recursive account.) I assume that the interpreter's theory has been adjusted to the evidence so far available to him: knowledge of the character, dress, role, sex, of the speaker, and whatever else has been gained by observing the speaker's behaviour, linguistic or otherwise. As the speaker speaks his piece the interpreter alters his theory, entering hypotheses about new names, altering the interpretation of familiar predicates, and revising past interpretations of particular utterances in the light of new evidence. (2006, p. 260)

Then, to assess how successful communication is arrived at, Davidson draws a distinction between the prior theory and the passing theory:

I have distinguished what I have been calling the prior theory from what I shall henceforth call the passing theory. For the hearer, the prior theory expresses how he is prepared in advance to interpret an utterance of the speaker, while the passing theory is how he does interpret the utterance. For the speaker, the prior theory is what he believes the interpreter's prior theory to be, while his passing theory is the theory he intends the interpreter to use. $(2006$, p. 260)

Therefore, the prior theory is determined by the context of the participants and it is different for each interlocutor. "It is quite clear that in general the prior theory is neither shared by speaker and interpreter nor is it what we would normally call a language" (Davidson 2006, p. 262). However, in general, the prior theory encompasses some common elements shared by both interlocutors, not only in relation to linguistic competence, but also to their knowledge of the other party. In contrast, the passing theory is established from the dialogic context, taking into account both this context and the prior theory. "The asymptote of agreement and understanding is when passing theories coincide" (Davidson 2006, p. 261). It is within the context of the dialogue that a speaker may make evasive moves and shift the burden of proof to the other party (usually through the literal 
meaning of the utterance/assertion). The listener, in an exercise of logica docens, then has to connect the two contexts (participants and dialogue) with the "mysterious" words by generating explanatory hypotheses; i.e., abducting the passing theory. In successful communication, the passing theory is the same for both parties; however, it is abductively provided and therefore is always revisable.

Let us examine a case in which the words lend new meaning that frames the issue at hand. The interpretation depends on knowledge of contextual factors. By virtue of that knowledge, hearers will adopt a new hypothesis about its possible meaning, or not.

The example involves misunderstanding and concerns an anecdote attributed to the writer and poet Francisco de Quevedo. It is said that, for queen Mariana of Austria, second wife of Philip IV of Spain, all comments related to her lameness made her very angry. It seems that Quevedo bet some friends over dinner that he would have the courage to call her "lame" in public. His plan was to make two bouquets: one of red roses and the other of white carnations. Once in the public square, Quevedo was presented to the Queen, and after paying obeisance, he offered her the two bouquets. Then, he addressed her with these gallant words: "Between the white carnations and the red roses, Her Majesty chooses." 2 It is difficult to translate this play on words. In Spanish, the feminine form of the word "lame" is "coja" and the correct form of the verb "to choose" used in this sentence is "escoja" = "is-lame". Therefore, in Spanish, "Her Majesty chooses" is phonetically identical to "Her Majesty is lame". Thus, Quevedo surely dined for free that night!

Before addressing the different pragmatic faces of Quevedo's utterance (one turned toward his fellows, other toward the Queen and an unwary audience), it is worth noting the role of some extra information given above and required for many readers to grasp how Quevedo plays on an equivocation by homophony: I had to provide a piece of meta-information to teach a non-Spanish speaking reader that "chooses" is translated as "es-coja" and this homophonic unit has two meanings. For most of the readers it is impossible to draw up the passing theory by themselves, since sufficient (and necessary) conditions for triggering readers' abduction are lacking. The fact that this extra information has been provided strongly emphasizes the important role of the speaker's (author's) assessment of the lis-

\footnotetext{
${ }^{2}$ The original statement in Spanish has the form of a rhyming couplet: "Entre el clavel blanco y la rosa roja, Su Majestad escoja."
} 
teners' (readers') prior theory and their abductive capacity to arrive at successful communication.

At this point, let us examine the example in context. (1) Quevedo's friends knew of his intention to publicly insult the queen (prior theory in "Quevedo's friends" context); therefore, they adopted an alternative to the ordinary hypothesis, i.e., the appropriate passing theory: "Her Majesty is lame". The interpreters, in this case Quevedo's friends, transformed the ordinary meaning of the statement, "to choose between a rose and a carnation" into a meaningless statement that seems, however, appropriate for Quevedo's intentions. Note that a similar statement, but without the wordplay, might be: "Between white carnations and red roses, Her Majesty is silly", which is clearly absurd.

(2) From the context of the Queen and the unwary audience in the public square, the poet gave the Queen a choice between a rose and a carnation: a subject addressing his Queen politely and courteously is actually what one would expect. In this case, Quevedo relied upon the Queen-audience's ignorance of the contextual elements (enclosed in Queen-audience's prior theory) to make his intentions invisible. The appropriateness of Quevedo's words given the context of the dialogue and the Queen-audience's prior theory prevents arrival at Quevedo's passing theory.

This case shows that many language strategies require an abductive capacity of the audience, they are required to escape the "routine" of prior theories. In any case, appropriate observation can alert us to the fact that the standard interpretation is not to be regarded as adequate; although we may not have enough elements to arrive at the appropriate passing theory.

\section{Ironic (Pseudo)Fallacy}

In this section, a case of ironic utterance is presented to connect interpretation, abduction and the dialectical approach to argumentation theory. This is a case proposed by García-Carpintero (2008) regarding what Grice (1975) called conversational implicature.

Begoña, who has certain feminist leanings, is driving a car and I accompany her. [...] The vehicle in front makes all kinds of unfortunate maneuvers of those types which exasperate other drivers. Finally, Begoña has the chance to overtake this car; in doing so, we both look with morbid curiosity at the driver of the other vehicle, perhaps trying to find some unmistakable sign of incompetence. The driver turns 
out to be a woman. Begoña then states: "It had to be a white car!" (pp. 492-493; my own translation from the original Spanish).

Begoña's statement poses an enigma. Conventionally, the statement emphasizes that it is a white car that made the unfortunate maneuvers. The expression "had to be" makes an association between this type of bad driving and white cars. Recalling Gricean conversational maxims, we can see that this statement violates several of them. First, Begoña lacks the appropriate data to make such a claim; and the statement does not appear to be relevant in that it is difficult to establish an association between the color of a car and the driver's inexperience. Therefore, we can infer that Begoña's assertion has all the appearance of the fallacy of poor generalization, i.e., an inference from a proven fact to an excessive generalization.

As in the example presented in Section 4, the intended meaning of Begoña's utterance has to be unraveled by the listener through an abduction which could provide the proper passing theory. This abduction will be inferred according to the contextual elements. Therefore, in order to examine the situation thoroughly, the listener has to follow a "method" to arrive at the hypothesis which leads to success in the communication process. Although audiences follow this method in a rather "unconscious" way, here I propose to analyze this case using the extended pragma-dialectics to provide a theoretical framework which addresses the context in a broad sense. By doing so, we can derive some tools to assess the value of the listener's abductive reasoning in the dialectical exchange. Moreover, the application of the theoretical norms of this perspective to utterances in which the intended meaning has to be unraveled may shed some light on assessing the interpretation process.

First, the listener tries to address the literal meaning of the utterance. Let us analyze this utterance using the extended pragmadialectics. I am considering Begoña's exclamation, therefore, as a contribution to a critical discussion. The implicit argument in this statement involves a pattern of reasoning from premises, in this case, this white car makes unfortunate maneuvers, to a conclusion: there is some connection between the color "white" and driving badly. From the pragma-dialectical perspective, this contribution violates rule VIII (if we were in the argumentative stage of the dialogue) of the decalogue proposed by van Eemeren and Grootendorst (1987), because the argumentative scheme is improperly applied. In particular, by justifying a general conclusion from an insufficient number of observations, this is a case of hasty generalization or secundum 
quid. But more interestingly, Begoña's words violate rules I and II, evading and shifting the burden of proof. The expression "had to be" in the assertion "invites" the listener not to argue with the issue. Considering Begoña's exclamation as a strategic maneuvering (van Eemeren 2010), the desire for efficiency ("had to be") undermines the level of reasonableness from the issue. From the literal meaning of the words, Begoña has committed a fallacy: some rules of the critical discussion have been violated or the strategic maneuvering has derailed.

At this point, the listener has detected a pragma-dialectical fallacy according to the literal meaning of Begoña's words. This detection warns us that we should review the words of our interlocutor to be sure that we have to address the literal interpretation, and not some other one.

At this stage, Begoña's interlocutor will search for a hypothesis which removes the conflict between the ordinary meaning of the utterance and the aims of a reasoned dialectical exchange. To clarify how abductive hypotheses are arrived at, I am going to consider different contextual situations. The protagonist of each context has to resolve the implicature in an exercise of logica docens, that is, to generate a passing theory from Begoña's words, the prior theory, and the context in question, i.e., to generate an abduction. Figure 1 (see p. 79) shows three argumentation schemes to the best explanation depending on these different contexts.

Context 1: Let us suppose that a third driver saw what happened and heard Begoña's words, but without knowing the sex of the driver of the white car. Certainly, this new actor would have considered Begoña's exclamation to be strange and misleading. How could these enigmatic words be explained, considering the few contextual data handled? The third driver might have guessed at various different scenarios, for example, "the girl in that car probably suffered some trauma caused by a white car" or "she has a superstitious prejudice against the color white". Notice that these attempts at an explanation cannot be confirmed by the driver because of the lack of pragmatic knowledge. This driver could not provide a plausible passing theory and the implicature remains unresolved. Thus from the perspective of the third driver, Begoña needs to explain her words; avoiding the burden of proof with her assertion would be fallacious. As we see, to solve the puzzle, the listener 
requires broader knowledge and, consequently, greater abductive capacity.

Context 2: We can imagine another context in which Begoña and I had shared some previous experiences. Let us suppose that, earlier that morning, we had read in the horoscope, among other niceties, that we have to be careful with "white things" over the coming days. Now Begoña's utterance/assertion fits with the horoscope predictions. The problem would be solved by identifying the passing theory with the prior theory, since the latter contains the shared knowledge; she might be kidding me or confirming the accuracy of astrological prediction. Once again, we would need a previous context to fully clarify the situation. "On this perspective, the strongest, or best explanation is the explanation that in a given context can be more hardly rejected by a counter-presumption" (Macagno and Walton 2013).

Context 3: Now, let us suppose that Begoña and I are friends, but nothing noteworthy related to the color white has happened previously. According to the contextual elements, I can propose a plausible explanation, since I have two key data that the third driver in context 1 did not have:

1. The driver of the white car is a woman.

2. Begoña struggles to combat the kind of prejudice that assumes that women are inferior to men when it comes to certain skills like driving.

In situations such as the one described, many men have said: "It had to be a woman!" to support the hypothesis that women are less competent drivers than men. Due to the second key fact I have to hand, I know that Begoña does not believe any such thing; and she knows, in turn, that I know. Based on the assumed abductive competence of her audience, Begona is saying: "Do not make use of spurious generalizations such as "there is a causal relationship between being female and driving badly'." Begoña's persuasive purpose is legitimate and, at this point, the hearer has recognized her real standpoint. In addition, the hearer also recognizes the strategic function of Begoña's maneuver: (a) by violation of rule VIII, the hearer realizes that the real standpoint has been presented by using an absurd argument which has the same form as what Begoña 
wants to denounce, and (b) by violation of rules I and II, Begoña invites the hearer to make the necessary contribution to appreciate her standpoint: listeners have to complete the reasoning, to see it for themselves. Here, the speaker's ironic utterance is understood as a strategic maneuvering in the discussion and an abductive trigger. This maneuver consists in violating the rules of critical discussion. The hearer notices that the dialogical rules have been broken and then adopts logica docens to perform the proper interpretation. Begoña's persuasive purpose, her strategic maneuvering, is legitimate: Begoña's statement is not, therefore, a pragma-dialectical fallacy. In addition, interestingly, the efficiency of her strategic maneuvering is mainly based on the listener's abductive capability.

In the light of these situations, an ironic utterance analyzed from the extended pragma-dialectics could be understood as an ironic (pseudo)fallacy. When we are faced with ironical speakers, the dialectical rules are "cleverly" violated to cause the desired effect in the audience. Therefore, the ironical speaker breaks the rules (commits a fallacy) as a strategic maneuvering in the discussion that acts as an abductive trigger. The hearer notices that the dialogic rules have been broken and then adopts a hypothesis through which to arrive at a proper interpretation. When this hypothesis arrived at by abduction coincides with the speaker's passing theory, the conflict caused by the violation of the dialectical rules will be removed. Therefore, for the hearer who arrives at the proper passing theory, the fallacy becomes an ironic (pseudo)fallacy. Interestingly, the efficiency of the strategic maneuvering is mainly based on the interlocutors' abductive abilities. In the case of the third driver, this strategic maneuvering is derailed due to the listener's abduction failing: there is no clear explanation for the violation of the dialectical rules that leads to successful communication. In this case, the hypothesis does not remove the conflict and the speaker's ironic (pseudo)fallacy continues to be a fallacy for the listener.

At this point, we may notice that in this case of ironic (pseudo)fallacy, the abductive process lasts only a few seconds. Whereas scientists or detectives could undertake an abductive process for several years, Begoña's companion solves the enigma quickly. Nevertheless, this rapid, almost instantaneous, new hypothesis arrived at by abduction could also be analyzed in a reasoned way. 


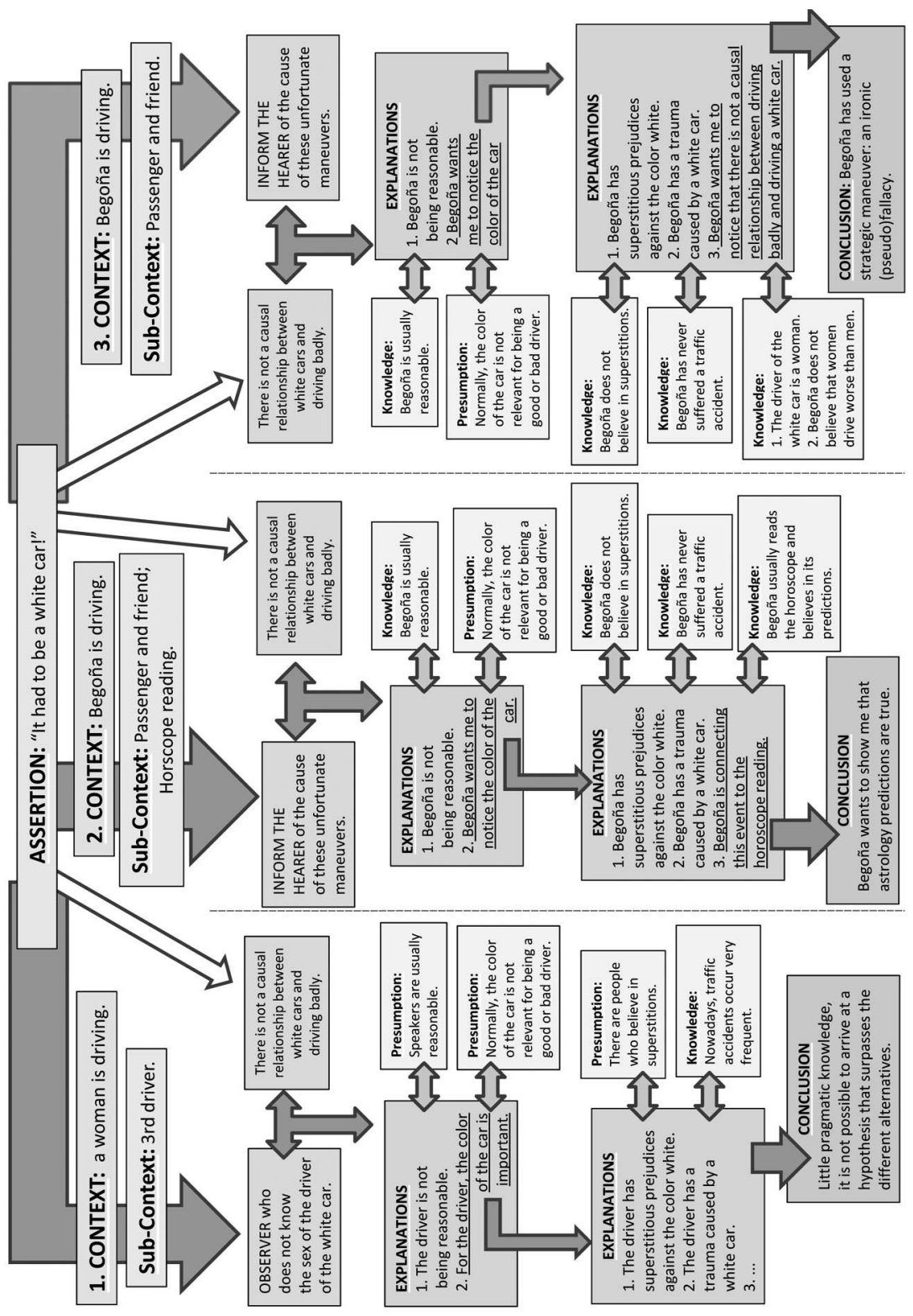


Figure 1 shows different argumentation schemes for the best explanation where the tension between explanation and knowledge/presumption moves the scheme in a certain direction. These schemes, which could be considered analogous to a persuasion dialogue or a critical discussion in solitude, offer the solution to the hypothesis of Begoña's companion. In these schemes, to provide a plausible hypothesis, a reticular set of abductive hypotheses capable of explaining the context is generated. In the absence of more data, the protagonist of each context reaches a conclusion by adopting an explanation that is more difficult to refute based on his/her presumptions or knowledge.

These alternative hypotheses have been proposed through a joint exercise of imagination and data analysis. From the first-level explanations (those that we see first in Figure 1) we choose that "Begoña wants me to notice the color of the car" because the alternative explanation "Begoña is not being reasonable" is strongly refuted by my knowledge. The second-level explanations (those derived later) may be more imaginative and, of course, depend on the observer. Nevertheless, the final conclusion has to be arrived at by a comparison of the different final alternatives (second-level explanations). For instance, if the protagonist of context 2 had noticed that the driver of the white car was a woman, equally plausible alternatives would have been generated at the second level of explanation (both the horoscope and ironic (pseudo)fallacy hypotheses) and the choice of the best explanation would have been determined by new contextual data.

Thinking of the scheme as a dialogue, it moves forward because the "parties" have taken on the burden of proof and have included or discarded in their commitment set the assertions that have been satisfactorily defended or refuted. Although a conclusion is reached quickly, reasoned dialogue is presented as an element that allows us to criticize the hypothesis adopted. We do not always want to evaluate the hypotheses arrived at by abduction, but if we do want to, it will be useful to follow the rules of the dialectical approach to argumentation.

\section{Conclusion}

Abduction helps us to correctly "guess" in our day-to-day lives. When we use language, we constantly deviate from the intent expressed by its standard or traditional use. We cannot use taxonomy 
to check what is said, just as we cannot carry out a standard treatment of fallacies. The interpretation of these deviations must consider many aspects: the different contexts (context of the dialogue, context of the participants), and the conventional or ordinary use of language, as well as an abductive capability that is more or less refined, depending on the case.

Ironic (pseudo)fallacy is an ironic utterance analyzed on the basis of extended pragma-dialectics. By an ironic (pseudo)fallacy, the ironical speaker breaks the dialectical rules as a strategic maneuvering in the discussion that acts as an abductive trigger; this (pseudo)fallacy utilizes ridiculous content to point out spurious arguments, shifts the burden of proof to the other party, and leaves the interlocutor to solve the riddle. To understand the "right" meaning, to reach the appropriate passing theory, abduction is required; therefore, an ironic (pseudo)fallacy is uttered based on the assumed abductive capability of the interlocutor. This abduction has to be inferred from the contextual elements, i.e., from one's knowledge at this point in the "investigation".

From the point of view of the hearer's abduction, this analysis proposes a vision where abduction is necessary in the interpretation process and also becomes fundamental for resolving a conversational implicature and for establishing whether someone is being pragma-dialectically fallacious. But more interestingly, in intentional deviations from the ordinary use of language and certain strategic maneuvers of argumentative discourse, the speaker, in order to communicate successfully or achieve the desired rhetorical effect, has to take into account the abductive capability of the audience. The speaker realizes that the passing theory can only be reached by means of abduction on the part of the listener; the "mysterious words" (conversational implicature, violation of pragma-dialectical rules or strategic maneuvering) trigger the abduction. In this analysis, the pragma-dialectical fallacy emerges depending not on the speaker's intention but on how the interpretation process has been carried out. Therefore, in the case of ironic (pseudo)fallacy, the speaker commits a fallacy (the derailment of the strategic maneuvering) only if the listener's abduction fails.

Finally, the analysis of deviations in a speaker's intent from that expressed by the standard or ordinary use of language on the basis of pragma-dialectics shows that the rules of the dialectical perspective on argumentation theory represent a useful tool that helps to evaluate 
properly hypotheses arrived at by abduction, even when they are derived in less than a second. ${ }^{3}$

\section{REFERENCES}

Aliseda, A., 2006, Abductive Reasoning. Logical Investigations into Discovery and Explanation, Springer, Dordrecht.

Anderson, D.R., 2005, "The Esthetic Attitude of Abduction", Semiotica, vol. 153, no. 1, pp. 9-22.

— 1986, "The Evolution of Peirce's Concept of Abduction", Transactions of the Charles S. Peirce Society, vol. 22, no. 2, pp. 145-164.

Arrighi, C. and R. Ferrario, 2008, "Abductive Reasoning, Interpretation and Collaborative Processes", Foundations of Science, vol. 13, no. 1, pp. 75-87.

Barés Gómez, C. and M. Fontaine, 2017, “Argumentation and Abduction in Dialogical Logic", in L. Magnani and T. Bertolotti (eds.), Handbook of Model-Base Science, Springer, Cham.

Chiasson, P., 2001, Logica Utens <http://www.digitalpeirce.fee.unicamp.br/ p-logchi.htm $>$ [retrieved: 30/05/2019].

Davidson, D., 2006, "A Nice Derangement of Epitaphs", in The Essential Davidson, Oxford University Press, New York.

Douven, I., 2011, “Abduction", The Stanford Encyclopedia of Philosophy (Spring 2011 Edition) in E.N. Zalta (ed.) <https://plato.stanford.edu/archives/spr 2011/entries/abduction/> [retrieved: 30/05/2019].

Doyle, A.C., 2009, The Case Book of Sherlock Holmes, eBooks@Adelaide, The University of Adelaide <https://ebooks.adelaide.edu.au/d/doyle/arthur_conan/d75ca/> [retrieved: 30/05/2019].

Duarte, A., 2018, "Abducción y logica docens", Revista de Filosofía, vol. 43 , no. 1, pp. 27-47.

—— 2015, "Abducción y diálogo persuasivo: Elemental, querido Peirce", Revista Iberoamericana de Argumentación, vol. 11, pp. 1-33.

Eco, U. and T.A. Sebeok (eds.), 1988, The Sign of Three: Dupin, Holmes, Peirce, Indiana University Press, Bloomington.

Fann, K.T., 1970, Peirce's Theory of Abduction, Martinus Nijhoff, The Hague.

Gabbay, D.M. and J. Woods, 2005, The Reach of Abduction. Insight and Trial, Elsevier, Amsterdam.

García-Carpintero, M., 2008, Las palabras, las ideas y las cosas, Ariel, Barcelona.

${ }^{3}$ I would like to thank the anonymous referees for their helpful reports that led to substantial improvements in the paper. I also gratefully acknowledge Claudia Chávez for her kindness during the revision process of this paper. 
Grice, H.P., 1975, "Logic and Conversation", in P. Cole and J.L. Morgan (eds.), Syntax and Semantics 3: Speech Acts, Academic Press, New York, pp. 41-58.

Hintikka, J., 1998, "What Is Abduction? The Fundamental Problem of Contemporary Epistemology", Transactions of the Charles S. Peirce Society, vol. 34, no. 3, pp. 503-533.

Macagno, F. and D. Walton, 2013, "Implicatures as Forms of Argument", in A. Capone, F. Lo Piparo and M. Carapezza (eds.), Perspectives on Pragmatics and Philosophy, Springer, Berlin, New York, pp. 203-224.

Magnani, L., 2009, “Abductive Cognition. The Epistemological and EcoCognitive Dimensions of Hypothetical Reasoning", in R. Dillmann, Y. Nakamura, S. Schaal, and D. Vernon, (eds.), Cognitive Systems Monographs, vol. 3, Springer, Berlin, Heidelberg.

- 2001, Abduction, Reason and Science. Processes of Discovery and Explanation, Kluwer Academic, Plenum Publishers, New York.

Niño, D., 2007, Abducting Abduction. Avatares sobre la comprensión de la Abducción de Charles S. Peirce, PhD dissertation, Universidad Nacional de Colombia.

Paavola, S., 2004, "Abduction as a Logic and Methodology of Discovery: The Importance of Strategies", Foundations of Science, vol. 9, pp. 267283.

Peirce, C.S., 1931-1958, Collected Papers of Charles Sanders Peirce, vols. 1-8, ed. P. Weiss, C. Hartshorne, and A.W. Burks, Harvard University Press, Cambridge, Mass. [CP].

Pietarinen, A.-V., 2005, "Cultivating habits of reason: Peirce and the logica utens versus logica docens distinction", History of Philosophy Quarterly, vol. 22 , no. 4 , pp. 357-372.

Van Eemeren, F.H., 2010, Strategic Maneuvering in Argumentative Discourse, John Benjamins Publishing Company, Amsterdam.

Van Eemeren, F.H. and R. Grootendorst, 1987, "Fallacies in PragmaDialectical Perspective", Argumentation, vol. 1, pp. 283-301.

- 1984, Speech Acts in Communicative Discussions, Foris, Dordrecht.

Wagemans, J.H.M., 2014, "The Assessment of Argumentation Based on Abduction", in D. Mohammed and M. Lewinśki (eds.), Virtues of Argumentation: Proceedings of the 10th International Conference of the Ontario Society for the Study of Argumentation (OSSA), 22-26 May 2013, OSSA, Windsor, ON.

Walton, D.N., 2004, Abductive Reasoning, The University of Alabama Press, Alabama.

Wirth, U., 2001, “Abductive Reasoning and Language Philosophy: Peirce's and Davidson's Account of Interpretation", in M. Bergman and J. Queiroz (eds.), The Commens Encyclopedia: The Digital Encyclopedia of Peirce Studies. New Edition, Pub. 121220-1059a < http://www.commens.org/encyclopedia/article/wirth-uwe-abductive-reasoning-and-languagephilosophy-peirces-and-davidsons $>$ [retrieved: 30/05/2019]. 
Yu, S. and F. Zenker., 2017, "Peirce Knew Why Abduction Isn't IBE. A Scheme and Critical Questions for Abductive Argument", Argumentation, vol. 32. no. 4, pp. 569-587.

Received: June 20, 2018; revised: May 15, 2019; accepted: May 24, 2019. 